\title{
OBITUARY
}

\section{Tribute to David Heaney}

\section{AUTHORS}

Philip Wilson ${ }^{1}$ DPhil FRCGP, Director, Centre for Rural Health *, p.wilson@abdn.ac.uk

John Howie ${ }^{2}$ MD, Emeritus Professor

Roger Strasser ${ }^{3}$ MBBS, BMedSc, MCISc, FRACGP, FACRRM, Founding Dean Emeritus, strasser@nosm.ca

David J Godden ${ }^{4}$ MD, Retired Physician and Researcher

Lewis Ritchie ${ }^{5} \mathrm{PhD}$

Frances Hines ${ }^{6}$ MSc, Manager

Christopher K Parker ${ }^{7}$ MA, Programme Manager for Project Development Support

\section{CORRESPONDENCE}

*Prof Philip Wilson p.wilson@abdn.ac.uk

\section{AFFILIATIONS}

${ }^{1}$ Institute of Applied Health Sciences, Centre for Health Sciences, University of Aberdeen, Inverness, Scotland IV2 3JH, UK

2 University of Edinburgh, Edinburgh, Scotland EH8 9YL, UK

${ }^{3}$ North Ontario School of Medicine, Sudbury, Ontario P3E2C6, Canada

${ }^{4}$ Retired, UK

${ }^{5}$ Centre of Academic Primary Care, University of Aberdeen, Aberdeen AB25 2ZD

6 Research, Development and Innovation, NHS Highland, Inverness IV2 7GE, UK

${ }^{7}$ Northern Periphery and Arctic Programme Secretariat, DK-1401 Copenhagen K, Denmark

\section{PUBLISHED}

9 August 2020 Volume 20 Issue 3

HISTORY

RECEIVED: 28 July 2020

ACCEPTED: 6 August 2020

\section{CITATION}

Wilson P, Howie J, Strasser R, Godden DJ, Ritchie L, Hines F, Parker CK. Tribute to David Heaney. Rural and Remote Health 2020; 20: 6326. https://doi.org/10.22605/RRH6326

\section{ETHICS APPROVAL}

Not applicable 


\section{FULL ARTICLE:}

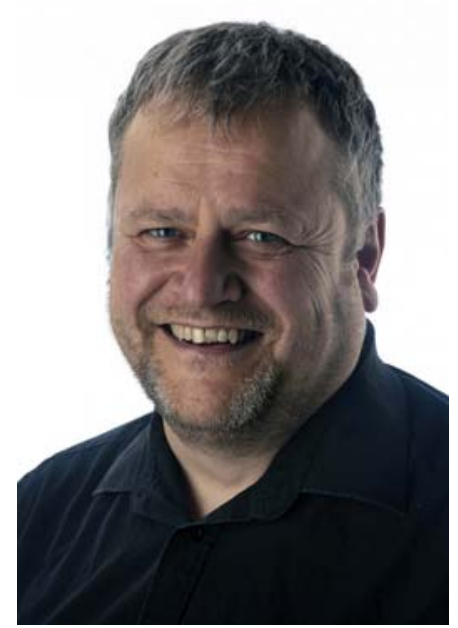

David Heaney died suddenly on 16 July 2020, aged 55. He was a major contributor to the development and evaluation of rural and remote health services in Scotland, and more widely in the Northern Periphery and Arctic (NPA) area and beyond. He will be greatly missed by his many colleagues and collaborators, many of whom became friends.

David was born in Liverpool to Northern Irish parents, who soon afterwards returned to Belfast and later to Portrush on the rural north coast of Ireland. He left Northern Ireland to study economics at Edinburgh University in 1983, following which he worked as a statistician in NHS Scotland's Information and Statistics division. In 1989, he moved into primary care academia, working as a research fellow in Professor John Howie's team in the world-leading Department of General Practice/Community Health Sciences at the University of Edinburgh. While in Edinburgh, David contributed to groundbreaking published research on self-care, patient enablement, telephone consulting and e-health in general practice.

In 2003, David moved north to the Scottish Highlands, to the University of Aberdeen's Inverness-based Centre for Rural Health, where he worked first as a senior research fellow and subsequently as associate director. It was in this post that he became involved in the development and evaluation of a broad range of initiatives to improve the health of rural people. David's contribution to the Centre for Rural Health was immense. He had a keen academic ability, combined with an intuitive and pragmatic approach to rural health issues. Living in the remote north-west Highlands and serving as a community first responder in his local area added to his understanding of clinical issues, and his opinion and guidance were highly respected by academics, frontline care providers and rural communities, as well as junior researchers who had the privilege to work with him.

He led and collaborated on many European regional program projects including Competitive Health Services (the EU Regio Star winner 2012), Older People for Older People, Implementing Transnational Telemedicine Solutions, Recruit and Retain, and Making it Work. Colleagues in these projects speak not only about his major contribution to the work, but also his thoughtful and calm approach. David was once quoted in a contribution that set the foundation for the programming philosophy for the NPA program 2014-2020: 'There is no point just exchanging knowledge unless you do something with it'. David's words were actionable and passionate, and so in the NPA program he continued to collaborate and mentor new projects such as SENDOC (Smart Sensor Devices for rehabilitation and Connected health) and CINE (Connected Culture and Natural Heritage in the Northern Environment).

As the COVID-19 pandemic began, he saw a need and initiated the NPA COVID-19 response group with support and more recently funding from the NPA Secretariat. He was in his element bringing together colleagues from Finland to Canada and the USA (and all countries in between) in the rural health field to respond synchronously to the COVID-19 pandemic. As lockdowns were implemented, David took some delight in observing that the rest of the world had joined him in working from home. The COVID-19 response group, a mixture of rurally based clinicians, administrators and researchers, quickly grew beyond the Arctic region to become a global network, exchanging information and developing new research.

At a more local level, David made important contributions to the development of out-of-hours care in remote and rural areas of Scotland as well as evaluation of primary care interventions more generally. He completed his PhD dissertation, 'Organisational change and remote and rural health care delivery: identifying the attributes of successful innovation', in 2014.

In 2015, David left the University of Aberdeen to direct his own company, Rossal Research and Consultancy, working from home in Ullapool. Rossal has played an important role in forging and supporting international health service research and development alliances across northern Europe, Canada and further afield, as well as in informing Scottish Government rural health policy. David worked increasingly closely with NHS Highland, particularly with its Research, Development and Innovation Division, both in Europeanfunded projects and in a consultancy capacity advising on service provision in rural areas. He was greatly valued by many colleagues across the health service.

In February 2020, David became a director of a new small enterprise: Highland Health Ventures Ltd. This company worked closely with NHS Highland to develop innovations to benefit patients, while bringing revenue to the health service. David was very active in his directorship and he brought in new products and funding within a few weeks of its set-up. His wide-ranging and 
innovative vision combined with a developing business acumen and enthusiasm for his new role meant he was central to the success of the business.

Key to the success of David's academic and service development work was his warm, jovial and open personality. He had a passionate commitment to tackling major health issues, particularly in the fields of remote health care and health inequalities, and his personal qualities enabled him to bring teams together to address these issues. Central to this process was his music. David was an accomplished guitar player who had played in several bands since his schooldays, most notably The Remains (a Ramones tribute band) and The Rogues (a Pogues tribute band). He will be missed by the Scottish Highlands music scene, and he had a special ability to forge a research team with his music in the bar after a day's formal workshop or conference proceedings.

David lived in Ullapool for more than 10 years, during which time he was actively involved in many aspects of the community, including as a founding member of the Lochbroom community radio. His radio colleagues spoke for many in the Ullapool community when they described him as generous, warm, switched on, a great guy and a pleasure to work with.

David leaves his wife, Lee, and his five sons (Connor, Thomas, Sean, James and Daniel), as well as his stepdaughter (Savanna), stepsons (Brendan and Pierce) and grandson (Lewis). His ex-partners (June Watson and Linda MacLeod) will also miss him greatly. He is also survived by his parents (James and Betty) and his brother (Stephen).

This PDF has been produced for your convenience. Always refer to the live site https://www.rrh.org.au/journal/article/6326 for the Version of Record. 